\title{
Tungsten-enhanced growth of Methanosphaera stadtmanae
}

\author{
Bédis Dridi ${ }^{1}$, Saber Khelaifia', Marie-Laure Fardeau², Bernard Ollivier ${ }^{2}$ and Michel Drancourt ${ }^{1 *}$
}

\begin{abstract}
Background: The methanogenic Archaea Methanosphaera stadtmanae has been detected in the human gut microbiota by both culture and culture-independent methods. Its growth reaches an exponential phase after 5 to 7-day culture in medium 322 (10\% vol). Our recent successful isolation of Methanomassiliicoccus luminyensis, a tungstate-selenite-requiring Archaea sharing similar metabolism characteristics with M. stadtmanae prompted us to study the effects of tungsten and selenium on M. stadtmanae growth.

Findings: Addition of $0.2 \mathrm{mg} / \mathrm{L}$ sodium tungstate to medium 322 yielded, 48 hours after inoculation, a growth rate equivalent to that obtained after 6 days with control culture as measured by methane monitoring and optical density measurement. Addition of $50 \mu \mathrm{g} / \mathrm{mL}$ sodium selenate had no effect on M. stadtmanae growth. Quantitative real-time PCRs targeting the $M$. stadtmanae $16 \mathrm{~S}$ rRNA confirmed these data.

Conclusions: These data provide new information regarding the poorly known nutritional requirements of the human gut colonizing organisms M. stadtmanae. Adding sodium tungstate to basal medium may facilitate phenotypic characterization of this organism and additionally aid the isolation of new Archaea from complex host microbiota.
\end{abstract}

Keywords: Methanogenic Archaea, Methanosphaera stadtmanae, Methanomassiliicoccus luminyensis, Tungsten, Selenium

\section{Findings}

Methanosphaera stadtmanae is a spherical-shaped, nonmotile archaeon initially isolated from human feces [1]. M. stadtmanae was the first human Archaea to be genome sequenced and analysis of the genome confirmed that M. stadtmanae belonged to Methanobacteriales [2]. PCR-based analyses further indicated that M. stadtmanaespecific sequences could be detected in stool specimen in up to $30 \%$ of individuals [3]. However, M. stadtmanae is a fastidious organism, with only one $M$. stadtmanae isolate reported and accordingly only one $M$. stadtmanae strain available in public collections. M. stadtmanae oxidizes hydrogen to reduce methanol into methane $[1,2]$. This metabolic trait has been already reported for $M$. stadtmanae [4], and more recently for members of the genus Methanobacterium (e.g. M. veterum and M. lacus;

\footnotetext{
* Correspondence: michel.drancourt@univmed.fr

'Unité de Recherche sur les Maladies Infectieuses et Tropicales Emergentes UMR CNRS 6236 IDR 198, IFR48, Institut Méditerranée Infection,

Aix-Marseille-Université, Marseille, France

Full list of author information is available at the end of the article
}

[5,6]) within the order Methanobacteriales. We recently isolated Methanomassiliicoccus luminyensis, the first cultured representative of new order of methanoarchaea [7]. This archaeon exhibits a metabolic trait similar to that of $M$. stadtmanae by using hydrogen as electron donor and methanol as electron acceptor [7]. Unexpectedly, we observed that addition of tungstate-selenite to culture medium had been a key factor for successful isolation of $M$. luminyensis and that this archaeon indeed required tungstate-selenite as an essential element for growth. We therefore tested the hypothesis that the addition of sodium tungstate or sodium selenate or both to basal culture medium would also enhance the growth of $M$. stadtmanae.

M. stadtmanae DSMZ $3091^{\mathrm{T}}$ (ATCC 43021 ${ }^{\mathrm{T}}$ ) purchased from the German Collection of Microorganisms and Cell Cultures (DSMZ, Braunschweig, Germany) was grown on medium 322 (http://www.dsmz.de) incubated at $37^{\circ} \mathrm{C}$ in Hungate tubes (Dutscher, Issy-les-Moulineaux, France) under 2-bar pressure of a $\mathrm{H}_{2} / \mathrm{CO}_{2}(80-20)$ atmosphere. The inoculated medium $(10 \%$ vol $)$ was 
incubated at $37^{\circ} \mathrm{C}$ with shaking. On the exponential phase of this first culture, a second inoculation was performed by $10 \%$ vol. in the same basal medium modified or not by the addition of $\mathrm{Na}_{2} \mathrm{O}_{4} \mathrm{~W}(0.2 \mathrm{mg} / \mathrm{L})$ and/or $\mathrm{Na}_{2} \mathrm{O}_{4} \mathrm{Se}(50 \mu \mathrm{g} / \mathrm{L})$ (Sigma, Saint-Quentin Fallavier, France). Non-inoculated media were used as negative controls and each experiment was repeated ten times.

Growth was assessed by optical microscope observation, parallel methane production measurement and measurement of the optical density of the medium. Methane production measurement used a GC-8A gas chromatograph (Shimadzu, Champs-sur-Marne, France) equipped with a thermal conductivity detector and a Chromosorb WAW 80/100 mesh SP100 column (Alltech, Carquefou, France). $\mathrm{N}_{2}$ at a pressure of $100 \mathrm{kPa}$ was used as the carrier gas. The detector and the injector temperatures were $200^{\circ} \mathrm{C}$, and the column temperature was $150^{\circ} \mathrm{C} . \mathrm{H}_{2}$ consumption and $\mathrm{CH}_{4}$ production were measured every 6 hours for 24 hours and then every 12 hours for 6 days. The optical density at $580 \mathrm{~nm}$ was measured by inserting Hungate tubes into the spectrophotometer (Varian Cary50; Agilent Technologies, Massy, France). Experiment was done in triplicate and average optical density value for the three replicates was calculated.

M. stadtmanae DNA extraction, quantification and sequencing were performed as previously described based on specific quantitative real-time PCR targeting $16 \mathrm{~S}$ rRNA gene [3].

Negative controls (with and without tungstate and selenium) remained negative with no growth occurring after one-week incubation indicating that results herein reported did not merely result from carry-over of organisms. The exponential phase of $M$. stadtmanae growth cultured in medium 322 was reached at 6-day incubation. At this point microscopic observation disclosed organisms with morphology compatible with $M$. stadtmanae and no contaminant. Also, qPCR detected an equivalent of $3.22 \mathrm{E}+12 \pm 1.53 \mathrm{E}+11$ copies of $16 \mathrm{~S}$ rRNA gene $/ \mathrm{mL}$ (Table 1). Sequencing of $16 \mathrm{~S}$ rRNA gene PCR products from all specimens yielded a sequence similarity of $99-100 \%$ with the reference $M$. stadtmanae DSM 3091 sequence.

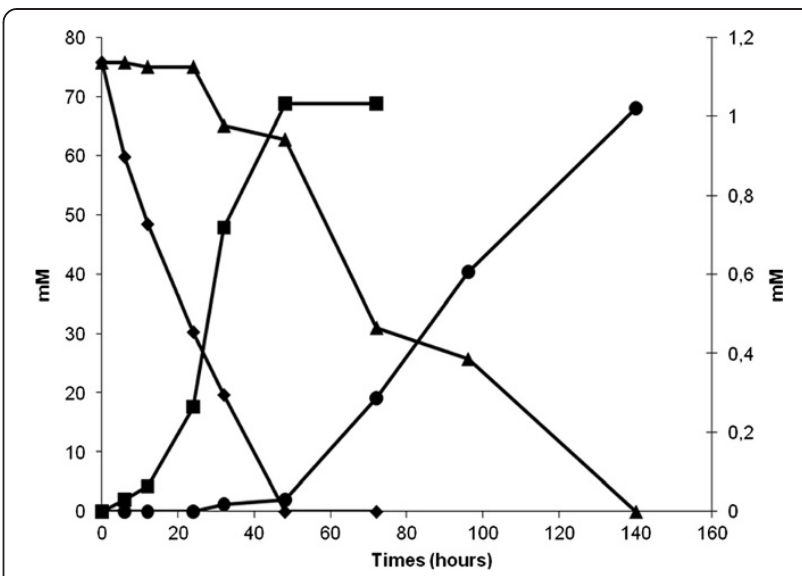

Figure 1 Visualizations of $\mathrm{H}_{2}$ used (in $\mathrm{mM}$; left $\mathrm{Y}$ axis) and $\mathrm{CH}_{4}$ (in $\mathrm{mM}$; right $\mathrm{Y}$ axis) produced by $M$. stadtmanae with and without addition of sodium tungstate solution $\left(\mathrm{Na}_{2} \mathrm{O}_{4} \mathrm{~W}\right)$ (over 140 hours ( $X$ axis). $\mathrm{H}_{2}$ used with sodium tungstate $\left(\mathrm{Na}_{2} \mathrm{O}_{4} W\right.$ ), - $\mathrm{CH}_{4}$ production with sodium tungstate $\left(\mathrm{Na}_{2} \mathrm{O}_{4} \mathrm{~W}\right)$, $\Delta \mathrm{H}_{2}$ used without sodium tungstate $\left(\mathrm{Na}_{2} \mathrm{O}_{4} \mathrm{~W}\right)$, and $\bullet \mathrm{CH}_{4}$ production without sodium tungstate $\left(\mathrm{Na}_{2} \mathrm{O}_{4} \mathrm{~W}\right)$.

The addition of sodium selenate alone has no effect on the growth curve of $M$. stadtmanae. However, the addition of sodium tungstate alone or in combination with sodium selenate shortened the lag period to 2 days post-inoculation with an equivalent 16S rRNA and rpoB genes copy number and with equivalent rates of methane production (Figure 1). In the absence of tungstate, M. stadtmanae exhibited a 30-hour log phase. Adding tungsate to the culture medium reduced the delay of this log-phase so that it took 47 hours instead of 72 hours to achieve a 0.35 optical density of the culture (Figure 2). These results correlated with the fact that M. stadtmanae genome encodes a formylmethanofuran dehydrogenase comprising of five sub-units (Genes IDs: 3855499-3855500-3855501-3855502-3855503), an enzyme found in methanogenic Archaea. In strict anaerobic micro-organisms, this enzyme catalyzes the reversible dehydrogenation of formylmethanofuran into $\mathrm{CO}_{2}$ and methanofuran. The formylmethanofuran dehydrogenases are either molybdenum- or tungsten-ironsulfur proteins. The tungsten is likely bound to the same

Table $1 \mathrm{M}$. stadtmanae $16 \mathrm{~S}$ rDNA gene copy number after 48-hour culture with $\mathrm{Na}_{2} \mathrm{O}_{4} \mathrm{~W}+\mathrm{Na}_{2} \mathrm{O}_{4} \mathrm{Se}$ or only $\mathrm{Na}_{2} \mathrm{O}_{4} \mathrm{~W}$ and a 6-day culture with no $\mathrm{Na}_{2} \mathrm{O}_{4} \mathrm{~W}+\mathrm{Na}_{2} \mathrm{O}_{4} \mathrm{Se}$ or only with $\mathrm{Na}_{2} \mathrm{O}_{4} \mathrm{Se}$ (Mean and standard deviation were calculated for 10 independent culture tests for each condition)

\begin{tabular}{|c|c|c|c|c|c|}
\hline & \multicolumn{3}{|l|}{ 48-hour culture } & \multicolumn{2}{|c|}{ 6-day culture } \\
\hline & without & with & with & with & without \\
\hline & $\overline{\mathrm{Na}_{2} \mathrm{O}_{4} \mathrm{~W}+\mathrm{Na}_{2} \mathrm{O}_{4} \mathrm{Se}}$ & $\overline{\mathrm{Na}_{2} \mathrm{O}_{4} \mathrm{~W}+\mathrm{Na}_{2} \mathrm{O}_{4} \mathrm{Se}}$ & $\mathrm{Na}_{2} \mathrm{O}_{4} \mathrm{~W}$ & $\mathrm{Na}_{2} \mathrm{O}_{4} \mathrm{Se}$ & $\mathrm{Na}_{2} \mathrm{O}_{4} \mathrm{~W}+\mathrm{Na}_{2} \mathrm{O}_{4} \mathrm{Se}$ \\
\hline Means & $2.13 \mathrm{E}+10$ & $4.42 \mathrm{E}+12$ & $3.93 E+12$ & $4.02 \mathrm{E}+12$ & $3.22 \mathrm{E}+12$ \\
\hline Standard deviation & $5.56 \mathrm{E}+09$ & $1.84 \mathrm{E}+11$ & $3.67 E+11$ & $2.23 E+11$ & $1.53 \mathrm{E}+11$ \\
\hline
\end{tabular}




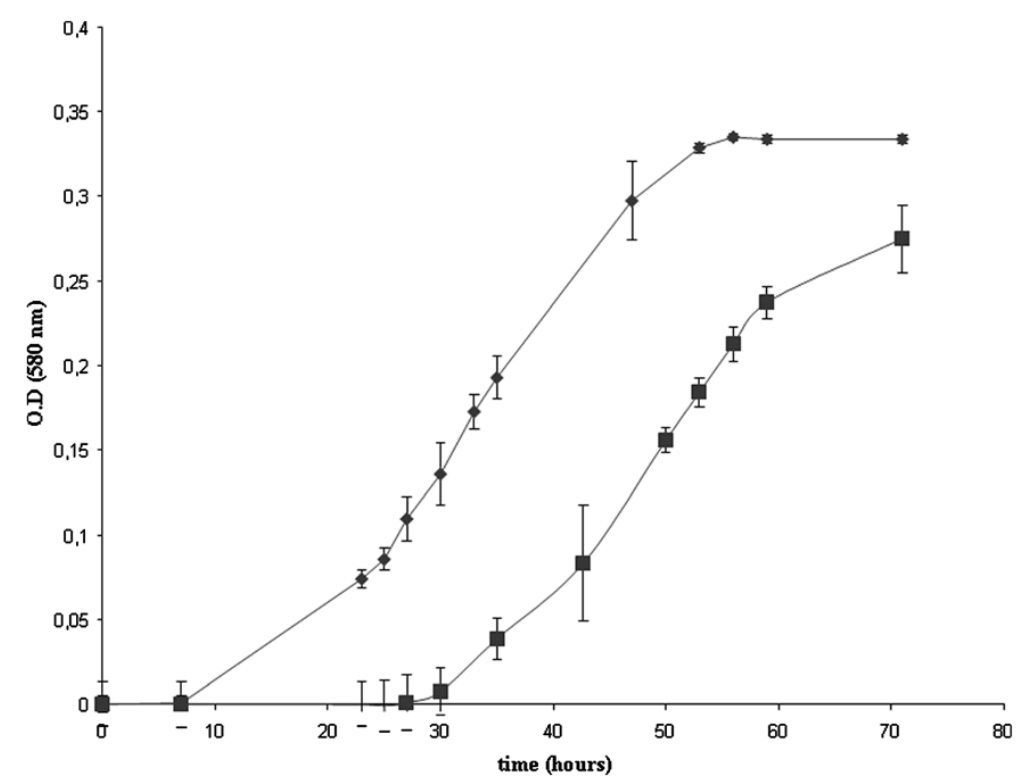

Figure 2 The effect of addition of selenite/tungstate solution on growth of $\boldsymbol{M}$. stadtmanae. Growth of $M$. stadtmanae with tungstate $\left(\mathrm{Na}_{2} \mathrm{O}_{4} \mathrm{~W}\right)$. Growth of M. stadtmanae without tungstate $\left(\mathrm{Na}_{2} \mathrm{O}_{4} \mathrm{~W}\right)$.

skeleton as the molybdenum in the so-called molybdopterin dinucleotide cofactor [8-10].

Previous reports described the requirement of tungsten for growing numerous methanogens including Methanothermobacter wolfei which has an obligate requirement for tungsten to maintain autotrophic growth, Methanococcus vannielii requiring tungsten as a cofactor for the enzyme formate dehydrogenase [11], Methanogenium tatii [12] and Methanocorpusculum parvum [13] also requiring tungsten for growth (Table 2). Selenium has also been reported as stimulatory and may be required for many methanogens, especially members of the genus Methanococcus as Methanococcus vannielii [11], Methanococcus jannaschii [14], Methanococcus maripaludis [15], Methanococcus voltae [16] and Methanococcus thermolithotrophicus [17] (Table 1). Requirement for selenium could have enzymatic basis, since it was reported that M. vannielii possesses a selenium-dependant formate

Table 2 Requirement of tungsten or/and selenium for growth of methanogens as reported in bibliography

\begin{tabular}{llll}
\hline Species & Tungsten & Selenium & References \\
\hline Methanothermobacter wolfei & YES & NA & {$[21]$} \\
\hline Methanococcus vannielii & YES & YES & {$[11,18]$} \\
\hline Methanogenium tatii & YES & NA & {$[12]$} \\
\hline Methanocorpusculum parvum & YES & NA & {$[13]$} \\
\hline Methanococcus jannaschii & NA & YES & {$[14]$} \\
\hline Methanococcus maripaludis & NA & YES & {$[15]$} \\
\hline Methanococcus voltae & NA & YES & {$[16]$} \\
\hline Methanococcus thermolithotrophicus & NA & YES & {$[17]$} \\
\hline
\end{tabular}

dehydrogenase [18]. Selenium was also reported as a component of both a hydrogenase [19] and tRNA [20].

In the absence of tungstate, $M$. stadtmanae exhibited a growth delay of 5-7 days which is long for testing in vitro susceptibility to antibiotics [22]. As we now observed that tungsten enhances the growth of two taxonomically unrelated methanogens, $M$. stadtmanae and $M$. luminyensis, we suggest that tungsten-containing media could be incorporated into the panel of media used for the isolation and culture of new methanogens from clinical and environmental specimens, and for testing their in-vitro susceptibility to antibiotics.

Methanogenic Archaea recently emerged as normal components of the human gastrointestinal and oral microbial ecosystems, where they could play important roles in health and diseases [23]. However, the isolation of such organisms requires long incubation times and strict anoxic atmosphere and is hampered by the incomplete knowledge of their nutritional requirements [23]. In fact, the result obtained in the present study may prompt further phenotypic characterization including extended antibiotic susceptibility testing [22] and even allowing isolation of new Archaea in order to assess understanding their contribution in the physiology of complex human microbiomes and their potential role in the course of infections.

\section{Competing interests}

The authors declare that they have no competing interests.

\section{Author's contributions}

$\mathrm{BD}, \mathrm{SK}, \mathrm{MLF}$ designed and performed analyses, BO, MD interpreted data and wrote the draft. All authors read and approved the final manuscript. 


\section{Author details}

'Unité de Recherche sur les Maladies Infectieuses et Tropicales Emergentes UMR CNRS 6236 IDR 198, IFR48, Institut Méditerranée Infection,

Aix-Marseille-Université, Marseille, France. ${ }^{2}$ Laboratoire de Microbiologie IRD, UMR D180, Microbiologie et Biotechnologie des Environnements Chauds, Aix-Marseille-Université, ESIL, Marseille, France.

Received: 16 November 2011 Accepted: 25 April 2012

Published: 15 May 2012

\section{References}

1. Miller TL, Wolin MJ: Methanosphaera stadtmaniae gen. nov., sp. nov.: a species that forms methane by reducing methanol with hydrogen. Arch Microbiol 1985, 141:116-122.

2. Fricke WF, Seedorf $H$, Henne $A$, Kruer $M$, Liesegang $H$, Hedderich $R$, et al: The genome sequence of Methanosphaera stadtmanae reveals why this human intestinal archaeon is restricted to methanol and $\mathrm{H} 2$ for methane formation and ATP synthesis. J Bacteriol 2006, 188:642-658.

3. Dridi B, Henry M, El Khéchine A, Raoult D, Drancourt M: High prevalence of Methanobrevibacter smithii and Methanosphaera stadtmanae detected in the human gut using an improved DNA detection protocol. PLoS One 2009, 4:e7063.

4. Kendall M, Boone D: The Order Methanosarcinales. In The Prokaryotes. Edited by Dworkin M, Falkow S, Rosenberg E, Schleifer KH, Stackebrandt E. New York: Spriger; 2006:244-256.

5. Krivushin KV, Shcherbakova VA, Petrovskaya LE, Rivkina EM: Methanobacterium veterum sp. nov., from ancient Siberian permafrost. Int J Syst Evol Microbiol 2010, 60:455-459.

6. Borrel G, Joblin K, Guedon A, Colombet J, Tardy V, Lehours AC, Fonty G: Methanobacterium lacus sp. nov., a novel hydrogenotrophic methanogen from the deep cold sediment of a meromictic lake. Int J Syst Evol Microbiol 2011, Sep 2. [Epub ahead of print] PubMed PMID: 21890730.

7. Dridi B, Fardeau ML, Ollivier B, Raoult D, Drancourt M: Methanomassiliicoccus luminyensis, gen. nov., sp. nov., a novel methanogenic Archaea isolated from human feces. Int I Syst Evol Microbiol 2012, 62:1902-1907. in press.

8. Karrasch M, Borner G, Enssle M, Thauer RK: The molybdoenzyme formylmethanofuran dehydrogenase from Methanosarcina barkeri contains a pterin cofactor. Eur J Biochem 1990, 194:367-372.

9. Karrasch M, Borner G, Enssle M, Thauer RK: Formylmethanofuran dehydrogenase from methanogenic bacteria, a molybdoenzyme. FEBS Lett 1989, 253:226-230.

10. Borner $G$, Karrasch M, Thauer RK: Molybdopterin adenine dinucleotide and molybdopterin hypoxanthine dinucleotide in formylmethanofuran dehydrogenase from Methanobacterium thermoautotrophicum (Marburg). FEBS Lett 1991, 290:31-34.

11. Jones JB, Stadtman TC: Methanococcus vannielii: culture and effects of selenium and tungsten on growth. J Bacteriol 1977, 130:1404-1406.

12. Zabel HP, König H, Winter J: Isolation and characterization of a new coccoid methanogen, Methanogenium tatii spec. nov. from a solfataric field on Mount Tatio. Arch Microbiol 1984, 137:308-315.

13. Zellner G, Alten C, Stackebrandt E, Conway De Macario E, Winter J: Isolation and characterization of Methanocorpusculum parvum gen. nov., spec. nov., a new tungsten requiring, coccoid methanogen. Arch Microbiol 1987, 147:13-20.

14. Jones WJ, Leigh JA, Mayer F, Woese CR, Wolfe RS: Methanococcus jannaschii sp. nov., an extremely thermophilic methanogen from a submarine hydrothermal vent. Arch Microbiol 1983, 136:254-261.

15. Jones WJ, Paynter MJB, Gupta R: Characterization of Methanococcus maripaludis sp. nov., a new methanogen isolated from salt marsh sediment. Arch Microbiol 1983, 135:91-97.

16. Berghöfer $Y$, Agha-Amiri K, Klein A: Selenium is involved in the negative regulation of the expression of selenium-free [NiFe] hydrogenases in Methanococcus voltae. Mol Gen Genet 1994, 242:369-373.

17. Belay N, Sparling R, Daniels L: Relationship of formate to growth and methanogenesis by Methanococcus thermolithotrophicus. Appl Environ Microbiol 1986, 52:1080-1085.

18. Jones JB, Stadtman TC: Selenium-dependent and selenium-independent formate dehydrogenases of Methanococcus vannielii. Separation of the two forms and characterization of the purified selenium-independent form. J Biol Chem 1981, 256:656-663.
19. Yamazaki S: A selenium-containing hydrogenase from Methanococcus vannielii, Identification of the selenium moiety as a selenocysteine residue. J Biol Chem 1982, 257:7926-7929.

20. Ching WM, Wittwer AJ, Tsai L, Stadtman TC: Distribution of two selenonucleosides among the selenium-containing tRNAs from Methanococcus vannielii. Proc Natl Acad Sci U S A 1984, 81:57-60.

21. König H, Semmler R, Lerp C, Winter J: Evidence for the occurrence of autolytic enzymes in Methanobacterium wolfei. Arch Microbiol 1985, 141:177-180.

22. Dridi B, Fardeau ML, Ollivier B, Raoult D, Drancourt M: The antimicrobial resistance pattern of cultured human methanogens reflects the unique phylogenetic position of archaea. J Antimicrob Chemother 2011, 66:2038-2044

23. Dridi B, Raoult D, Drancourt M: Archaea as emerging organisms in complex human microbiomes. Anaerobe 2011, 17:56-63.

doi:10.1186/1756-0500-5-238

Cite this article as: Dridi et al:: Tungsten-enhanced growth of Methanosphaera stadtmanae. BMC Research Notes 2012 5:238.

\section{Submit your next manuscript to BioMed Central and take full advantage of:}

- Convenient online submission

- Thorough peer review

- No space constraints or color figure charges

- Immediate publication on acceptance

- Inclusion in PubMed, CAS, Scopus and Google Scholar

- Research which is freely available for redistribution 